\title{
An Unusual Case of Hemolytic Disease of Newborn Due to ABO and Rh Isoimmunization
}

\author{
Suman S. Routray ${ }^{1}$, Jagdish P. Sahoo ${ }^{2}$, Rachita Behera ${ }^{3}$, Devi Acharya ${ }^{4}$, Girija N. Kanungo ${ }^{3}$ \\ 1. Transfusion Medicine, All India Institute of Medical Sciences, Bhubaneshwar, Bhubaneswar, IND 2. Neonatology, \\ Institute of Medical Sciences (IMS) and SUM Hospital, Bhubaneswar, IND 3. Transfusion Medicine, Institute of Medical \\ Sciences (IMS) and SUM Hospital, Bhubaneswar, IND 4. Transfusion Medicine, AMRI Hospital, Bhubaneswar, IND
}

Corresponding author: Suman S. Routray, routray.sumansudha@gmail.com

\begin{abstract}
Anti-D is the most common cause of hemolytic disease of the newborn (HDN) in the developing countries even after the introduction of anti-D immunoprophylaxis. Still, ABO incompatibility and other alloantibodies against minor blood group antigens have emerged as significant causes of HDN. Moreover, $\mathrm{ABO}$ incompatibility acts as a protective barrier to the expression of $\mathrm{Rh}$ isoimmunization. Here we are presenting a case of $\mathrm{HDN}$ where both Rh and $\mathrm{ABO}$ incompatibility co-existed with their manifestations in a $\mathrm{B}$ positive neonate born to an $\mathrm{O}$ positive mother. Use of appropriate elution technique can aid in the diagnosis of such cases. Hence, antenatal screening of all mothers irrespective of their Rh D status can help in early diagnosis and proper management that can decrease the neonatal morbidity and mortality.
\end{abstract}

Categories: Pathology, Allergy/Immunology, Hematology

Keywords: hemolytic disease of the newborn, abo incompatibility, rh isoimmunisation, hyperbilirubinemia

\section{Introduction}

Hemolytic disease of the newborn (HDN) occurs as a result of immune-mediated destruction of red cells leading to increase mortality and morbidity in neonates. $\mathrm{ABO}$ incompatibility has emerged as a significant cause of HDN in the western world after the introduction of prophylactic anti-D administration [1]. Studies have demonstrated that in the presence of major $\mathrm{ABO}$ incompatibility between mother and fetus, the incidence of $\mathrm{D}$ isoimmunization is less in mother. This is apparently due to the hemolysis of $\mathrm{ABO}$ incompatible red cells of the fetus in the mother's circulation before the recognition of the Rh incompatible antigen by the mother's immune system. Here we report a case of a hemolytic disease of newborn caused by the coexistence of both $\mathrm{ABO}$ and $\mathrm{Rh}$ incompatibility.

\section{Case Presentation}

A multigravida mother (G5A4L0) with the bad obstetric history presented at 32nd week of gestation to our hospital with the complaint of decreased fetal movement. She had a history of receiving 11 transfusions during her past abortions. Because of fetal distress, emergency caesarian section (LSCS) was performed, and a baby girl weighing $1.9 \mathrm{~kg}$ was delivered. The baby was transferred to the neonatal intensive care unit (NICU) on day 1 for preterm care and was started on full feeding. She developed anaemia and jaundice on day 3 during her stay at NICU.

On routine investigations, the laboratory findings were as follows: total serum bilirubin was $11.3 \mathrm{mg} / \mathrm{dl}, \mathrm{Hb}$ $14.3 \mathrm{gm} / \mathrm{dl}$ and reticulocyte count $4.8 \%$. Peripheral smear reported features of hemolytic anaemia. G6PD estimation was performed and found to be 14.8 units/g of $\mathrm{Hb}$ (within standard limit). Thyroid profile was normal. Because of suspected HDN, a blood sample was sent to the department of transfusion medicine for immunohaematological work up.

The forward blood group of the neonate was B Rh D positive with the gold standard tube technique, and that of the mother was O Rh D positive by both forward and reverse grouping. Polyspecific direct antiglobulin test (DAT) by column agglutination technique (Anti Human Globulin gel card containing IgG + C3d component, BIORAD) showed $4+$ reaction. Monospecific DAT using IgG + C3d gel card (Tulip Diagnostics) showed IgG specificity with C3d and control being negative. Glycine-hydrochloride acid elution was done using Gamma Elu-Kit (Biorad, Switzerland). The eluate from DAT positive red cells was tested against commercialized available $0.8 \%$ three cell panel (DIACELL I-II-III, Biorad, Switzerland). It was found to be reactive in panel II and III. On antibody identification using commercially available 11 cell panel (Biorad, Switzerland), anti-c was detected (Figure 1, Table 1). 


\section{Cureus}

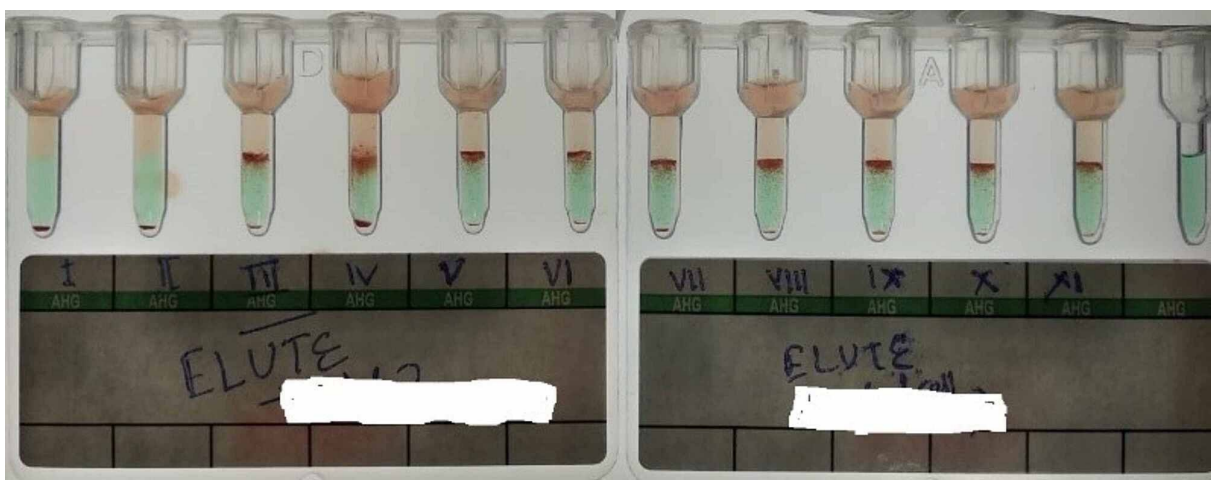

FIGURE 1: Antibody Identification of Neonate's Eluate Showing Anti-c Specificity.

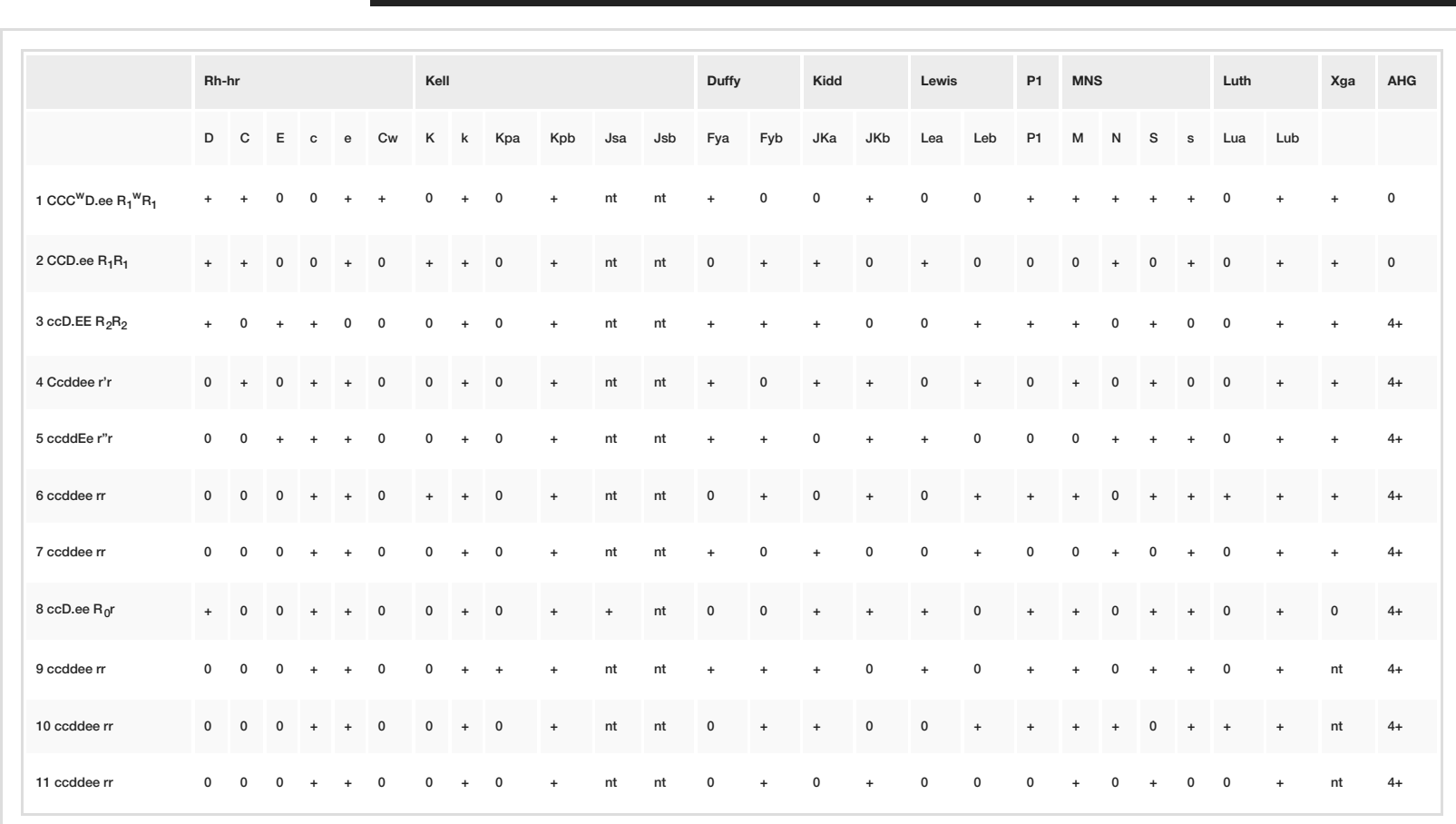

TABLE 1: Antibody Identification Panel for Eluate of Neonate Showing Anti-c Specificity.

Presence of anti-E was ruled out by using select cells (c-E+, c+E-). Heat elution at $560 \mathrm{C}$ for 10 minutes using $6 \%$ albumin with intermittent agitation on the neonate red blood cells was performed. The eluate, when tested against freshly prepared $5 \%$ cell suspension of c negative A, B and O pooled cells, showed specificity to anti-B at AHG phase confirming the diagnosis of ABO HDN (Figure 2). 


\section{Cureus}

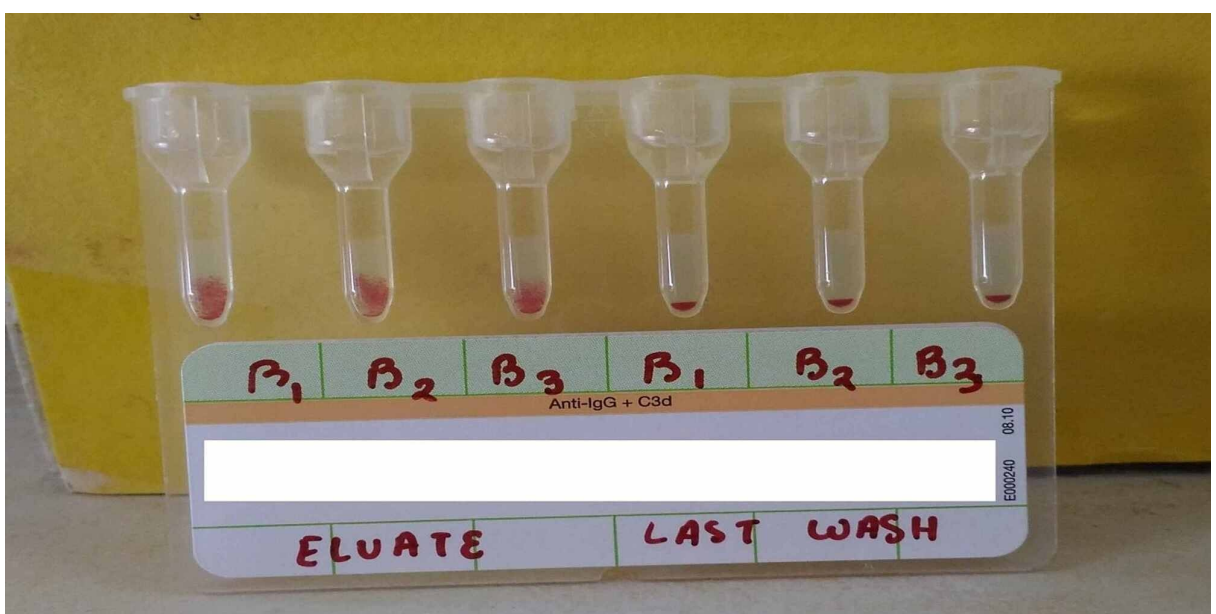

FIGURE 2: Antibody Identification of Neonate's Eluate Showing Anti-B Specificity.

To confirm the anti-c alloantibody, which was transferred from the mother, maternal serum was tested for antibody screening and identification. Anti-c was detected with a titre of 16 at AHG phase. Anti-B titre was 1048 at AHG phase.

On extended RH-Kell phenotyping, the mother was found to be C+ c- E- e+, K-, father C- c + E- e +, K - and that of the baby was $\mathrm{C}-\mathrm{c}+\mathrm{E}-\mathrm{e}+, \mathrm{K}$. Baby received phototherapy and was discharged with a stable vitals.

\section{Discussion}

Here we have reported a rare case of HDN where hemolysis of red cells was due to anti-c and anti-B. Many works of the literature suggest that $\mathrm{ABO}$ incompatibility protects somewhat against $\mathrm{Rh}$ isoimmunization. The maternal IgG antibodies that cross the placenta causing HDN could be naturally occurring (Anti A, Anti B) or immune antibodies developed following sensitization event. This happens in $15-20 \%$ of all pregnancies. In the case of $\mathrm{ABO} \mathrm{HDN}$, the fetal red cells were destroyed by the maternal reticuloendothelial system as soon as the fetal red cells entered the maternal circulation by the natural occurring anti-A/anti-B. So the development of an antibody against $\mathrm{Rh}$ antigen is not possible. A high titer of these immune antibodies may not present with adverse effects in utero as A and B antigens are present on cells of all other tissues and body fluid and not only on red cells. The presence of these antigens helps to protect the incompatible fetal red cells by neutralizing the transferred maternal antibody with small amounts of an antibody reacting directly with the fetal red cells [2]. The red cells which are sensitized by the antibodies are destroyed by macrophages in the fetal spleen with consequent hyper-bilirubinemia in about $10 \%$ of cases $[3,4]$. With the widespread use of RhD immunoglobulin, the focus has shifted to the non-RhD antibodies causing isoimmunization. Other Rh antigens include $\mathrm{C}$, c, E, and e antigens. DCe is the most common haplotype in Caucasians (42\%), Native Americans (44\%), Asians (70\%) [5], and also among Indians (40.9\%) [6].

The severity of hyperbilirubinemia (total bilirubin $14.3 \mathrm{gm} / \mathrm{dl}$ ) is more in $\mathrm{Rh} \mathrm{HDN}$ in comparison to ABO HDN [7]. In this case, the previous history of multiple transfusion and abortion was a concern for alloantibodies (Rh/Non-Rh HDN). So glycine-acid elution was performed and from the elute anti-c was detected. Whether the development of Rh alloimmunization (anti-c) in mother has occurred as a result of previous pregnancies or transfusions was inconclusive. Around 3.77\% of pregnant mothers with bad obstetric history have a risk of developing alloimmunization [8]. Red cell alloimmunization among expectant mothers is widely studied around different parts of the world, ranging from $0.4 \%$ to $2.7 \%$ and anti-E, anti-c, anti-kell are the most common alloantibodies among Rh D positive pregnant women [9-13]. Anti-c was identified to cause severe HDN in about $10 \%$ of pregnancies with c+ foetus in Netherland [11]. Anti-E, anti-C and anti-e are generally implicated with a mild form of Rh HDN [14]. Anti-c is the second most antibody commonly encountered in Rh D positive Indian mothers with high-risk pregnancies or with a history of transfusion that affects fetus resulting in HDN [15]. ABO HDN is more common among neonates of O blood group mothers as naturally occurring IgG anti-A/anti-B is more prevalent with a significant high titre [16]. In our case, the mother was O positive, and the baby was B positive. So ABO HDN was in suspicion. So heat elution was performed, and anti-B was detected in elute. Both heat elution and glycine acid elution confirmed the case to be the existence of both ABO and Rh HDN. Some literature also mentioned about the utility of heat elution in the detection of $\mathrm{Rh} / \mathrm{Non}$ - $\mathrm{Rh}$ alloantibodies though not superior to glycine-acid elution [17]. Presence of $\mathrm{c}$ antigen on RBC of father/baby and absence on RBC of the mother was also a corroborative finding to support the development of anti-c in the mother which transferred to the baby through the placenta. 
Mina et al. reported a case of HDN due to Rh anti-c in an infant of an Rh-positive mother, who required double volume exchange transfusion (DVET) [18]. Here the patient was managed by phototherapy only without the need of DVET. This could be explained by the fact that ABO HDN might have masked the effect of Rh alloimmunization.

\section{Conclusions}

The diagnosis, acute management, and follow-up of neonates with HDN still represent an important area of activity for maternity/neonatal services. With the introduction of RH D immunization, the chances of Rh D HDFN has been on reversal trend. Consequently, hemolytic disease due to $\mathrm{ABO}$ incompatibility and other alloantibodies along with Rh alloantibodies have taken centre stage. Antibody screening regularly of all pregnant women is now implemented in many developed countries as a part of the national program, which aids in the appropriate management. All the pregnancies irrespective of $\mathrm{Rh} \mathrm{D}$ status should be screened in developing countries like India to reduce the morbidity and mortality related to HDN. Moreover, early detection of antibody aids in the appropriate transfusion support with the antigen-negative unit if needed.

\section{Additional Information \\ Disclosures}

Human subjects: Consent was obtained by all participants in this study. Conflicts of interest: In compliance with the ICMJE uniform disclosure form, all authors declare the following: Payment/services info: All authors have declared that no financial support was received from any organization for the submitted work. Financial relationships: All authors have declared that they have no financial relationships at present or within the previous three years with any organizations that might have an interest in the submitted work. Other relationships: All authors have declared that there are no other relationships or activities that could appear to have influenced the submitted work.

\section{Acknowledgements}

We are very much thankful to all the staffs of the Department of Transfusion Medicine, IMS and SUM Hospital, Bhubaneswar for their support.

\section{References}

1. Basu S, Kaur R, Kaur G: Hemolytic disease of the fetus and newborn: current trends and perspectives . Asian J Transfus Sci. 2011, 5:3-7. 10.4103/0973-6247.75963

2. Ottenberg R: Studies in isoagglutination: I. Transfusion and the question of intravascular agglutination . J Exp Med. 1911, 13:425-438. 10.1084/jem.13.4.425

3. Hadley AG: Laboratory assays for predicting the severity of haemolytic disease of the fetus and newborn Transpl Immunol. 2002, 10:191-198. 10.1016/S0966-3274(02)00065-5

4. Nagashree U, Swetha P, Manohar S, Parthasarathy LK: ABO incompatibility: its impact on pregnancy and neonate. Int J Reprod Contracept Obstet Gynecol. 2019, 8:766-768. 10.18203/2320-1770.ijrcog20190321

5. Dean L: The Rh blood group. In: Blood Groups and Red Cell Antigens. National Library of Medicine, Bethesda; 2006. 1-6.

6. Makroo R, Gupta R, Bhatia A, Rosamma NL: Rh phenotype, allele and haplotype frequencies among 51,857 blood donors in North India. Blood Transfus. 2014, 12:36-39. 10.2450/2013.0300-12

7. Bi SH, Jiang LL, Dai LY, et al.: Rh-incompatible hemolytic disease of the newborn in Hefei . World J Clin Cases. 2019, 7:3202-3207. 10.12998/wjcc.v7.i20.3202

8. Agrawal A, Mathur A, Dontula S, Jagannathan L: Red blood cell alloimmunization in multi - transfused patients: a bicentric study in India. Global J Transfus Med. 2016, 1:12-15. 10.4103/2455-8893.178005

9. Velkova E: Correlation between the amount of anti-D antibodies and IgG subclasses with severity of haemolytic disease of foetus and newborn. Open Access Maced J Med Sci. 2015, 3:293-297. 10.3889/oamjms.2015.058

10. Al-Dughaishi T, Al-Rubkhi IS, Al-Duhli M, Al-Harrasi Y, Gowri V: Alloimmunization due to red cell antibodies in Rhesus positive Omani pregnant women: maternal and perinatal outcome. Asian J Transfus Sci. 2015, 9:150-154. 10.4103/0973-6247.162710

11. Koelewijn JM, Vrijkotte TGM, van der Schoot CE, Bonsel GJ, de Haas M: Effect of screening for red cell antibodies, other than anti-D, to detect hemolytic disease of the fetus and newborn: a population study in the Netherlands. Transfusion. 2008, 48:941-952. 10.1111/j.1537-2995.2007.01625.x

12. Jerković Raguž M, Šumanovic Glamuzina D, Brzica J, Gruica T: The incidence and effects of alloimmunization in pregnancy during the period 2000 - 2013. Geburtshilfe Frauenheilkd. 2017, 77:780-785. 10.1055/s-0043-109867

13. Hassan MN, Mohd Noor NH, Johan Noor SR, Sukri SA, Mustafa R, Luc Aster HV: Hemolytic disease of fetus and newborn due to maternal red blood cell alloantibodies in the Malay population. Asian J Transfus Sci. 2014, 8:113-117. 10.4103/0973-6247.137449

14. Abourazzak S, Hajjaj S, Hakima C, Bouharrou A, Hida M: Haemolytic disease of the newborn due to anti-c . BMJ Case Rep. 2009, 2009:Bcr09.2008.0987. 10.1136/bcr.09.2008.0987

15. Sankaralingam P, Jain A, Bagga R, Kumar P, Marwaha N: Red cell alloimmunization in RhD positive pregnant women and neonatal outcome. Transfus Apher Sci. 2016, 55:153-158. 10.1016/j.transci.2016.06.002

16. Murray NA, Roberts IA: Haemolytic disease of the newborn. Arch Dis Child Fetal Neonatal Ed. 2007, 92:8388. 10.1136/adc.2005.076794 


\section{Cureus}

17. Katharia R, Chaudhary RK: Removal of antibodies from red cells: comparison of three elution methods . Asian J Transfus Sci. 2013, 7:29-32. 10.4103/0973-6247.106727

18. Mina SS, Bhardwaj R, Gupta S: Hemolytic disease of newborn: can think beyond Rh (D) and ABO incompatibilities. J Clin Neonatol. 2017, 6:37-39. 10.4103/2249-4847.199756 